\title{
Electrochemistry in Liquid Ammonia. VII. Halonitrobenzenes
}

\author{
TOWFIK TEHERANI and ALLEN J. BARD
}

Department of Chemistry, University of Texas, Austin, Texas 78712, U.S.A.

The reduction of halonitrobenzenes $(\mathrm{RX})(o-$, $m-, p-\mathrm{Cl} ; m-\mathrm{Br} ; o-, m-, p-\mathrm{I})$ in liquid ammonia, $0.1 \mathrm{M} \mathrm{KI}$ at a platinum electrode was investigated by cyclic voltammetric and controlled potential coulometric techniques. In this medium the radical anions, $\mathbf{R X}^{-}$, were much more stable compared to other nonaqueous systems; for example, the $m-\mathrm{Cl}$ and $p$-Cl radical anions were stable on the coulometric time scale (lifetimes $\gg 30 \mathrm{~min})$. The dianions of most of these $\left(\mathrm{RX}^{2-}\right)$ underwent rapid loss of halide ion; however, the dianion of $m$-chloronitrobenzene was stable. Estimates of the rate constants for the loss of halide by the dianions are given.

The electrochemical reduction of halogenated aromatic compounds has been discussed in numerous reports ${ }^{1-14}$ and especially exhaustively in Ref. 1. In general, the reduction process of aryl halides can be represented by the following reaction scheme:

$$
\begin{aligned}
& \mathrm{RX}+\mathrm{e} \rightarrow \mathrm{RX}^{-} \\
& \mathrm{RX}^{--} \stackrel{k}{\rightarrow} \mathrm{R}^{-}+\mathrm{X}^{-} \\
& \mathrm{R}^{\cdot}+\mathrm{e} \rightarrow \mathrm{R}^{-} \\
& \mathrm{R}^{-}+\mathrm{HS} \rightarrow \mathrm{RH}+\mathrm{S}^{-}
\end{aligned}
$$

where HS is a solvent.

The rate of the halogen cleavage process depends upon the solvent, the nature of the halogen and its position on the aromatic ring, and the presence of various other substituents on the molecule. The stability of the radical anions formed by electron uptake is enhanced by increasing the odd electron's delocalization through the presence of electron-withdrawing groups $\left(-\mathrm{NO}_{2},-\mathrm{CN}\right)$. The potential for reduction of the neutral radical $\left(R^{*}\right)$ is usually more positive than that of the parent (RX) leading ultimately to the formation of a carbanion which is rapidly protonated by the solvent. In dimethylformamide (DMF), acetonitrile (MeCN), and dimethyl sulfoxide (DMSO), there has been evidence that $R$. (the product of reaction 2) can undergo a hydrogen abstraction reaction involving the solvent:

$$
\mathrm{R} \cdot+\mathrm{HS} \rightarrow \mathrm{RH}+\mathrm{S}
$$

The hydrogen abstraction mechanism usually results in an apparent number of electrons passed in a coulometric reduction of less than 2 . This also leads to formation of solvent-substituted products produced by a variety of reaction paths involving $R^{\prime}$ and $S^{*}$. In certain cases, where the radical anion of the halogenated parent $\left(\mathrm{RX}^{-}\right)$is more stable, other reaction pathways, including disproportionation, are possible:

$$
\begin{aligned}
& \mathbf{R}^{\cdot}+\mathbf{R X}^{-} \rightarrow \mathrm{R}^{-}+\mathrm{RX} \\
& \mathbf{R}^{-}+\mathrm{HS} \rightarrow \mathrm{RH}+\mathrm{S}^{-}
\end{aligned}
$$

This overall reaction pathway is indistinguishable from the mechanism represented by reactions (1)-(4). The final product is the same and involves the addition of 2 electrons and 1 proton per molecule.

The formation of stable radical anions of certain members of a series of halogenated benzophenones and fluorenones in DMF, DMSO, and ACN have been reported. ${ }^{5,11,15}$ In fact, such radicals were sufficiently long-lived to 
permit their detection by ESR and the measurement by cyclic voltammetry and polarography of the standard potential, $E^{\circ}$, for the $\mathrm{RX} / \mathrm{RX}^{-}$ couple. The stability of the $\mathrm{RX}^{-}$can be measured by lowering the temperature, thus slowing down the halogen cleavage rate and retarding side reactions with impurities and solvent. ${ }^{6,16}$ Liquid $\mathrm{NH}_{3}$ has been shown to be a suitable solvent to investigate the halogen cleavage process in the absence of possible hydrogen abstraction. The reduction of a series of halobenzophenones in $\mathrm{NH}_{3}$ has been reported. ${ }^{10}$ The enhanced stability of the generated radical ions observed in liquid $\mathrm{NH}_{3}$ was attributed to the low temperature $\left(-40^{\circ} \mathrm{C}\right)$ conditions of the experiment. However, stable dianions were also easily formed in this solvent. This has not been possible in other nonaqueous solvents, such as DMF and MeCN.

The electrochemical reduction of halonitrobenzenes in ACN, DMF and DMSO has been described. ${ }^{4,14}$ In all cases, the reduction process involved the formation of the corresponding radical anion and halide ion. Nitrobenzene, which is the main reaction product, is formed by hydrogen atom abstraction from either the solvent or the supporting electrolyte. The proposed reaction mechanism was consistent with an ECEtype mechanism (chemical reaction between electron transfer processes). ESR experiments involving in situ generation of halogenated nitrobenzene radical anions in $\mathrm{CD}_{3} \mathrm{CN}$ confirmed that the abstraction of the hydrogen atom is, in fact, from the solvent and not from the supporting electrolyte. ${ }^{6}$ The relative decomposition rates of the radical anions increased in the order:

$o$-iodo $>o$-bromo $>>p$-iodo $>m$-iodo.

The fast kinetics associated with the halogen cleavage step at room temperature prevented the investigation of the electrogenerated radical anion. For this reason, low temperature electrochemical studies were performed in an attempt to isolate the one-electron transfer reduction. At $-19{ }^{\circ} \mathrm{C}$, the rates of follow-up chemical reactions were sufficiently slowed that a cyclic voltammogram of $p$-iodonitrobenzene, for example, indicated a one-electron reversible wave. Information about the lifetimes of unstable radical anions of aromatic halides has also recently been obtained by utilizing homogeneous redox catalysis reactions for generation of $\mathrm{RX}^{-2}$.
The previous studies produced little or no information regarding the stabilities of the dianions. In fact, protonation was so rapid that dianions were not detected even at relatively low temperatures. Past investigations from this laboratory of the reduction of several compounds (nitrobenzene, nitrosobenzene and benzophenone) in liquid $\mathrm{NH}_{3}$ demonstrated that this solvent was useful for the formation of stable radical anions and dianions. ${ }^{17-20}$ In the study reported here, we extend this solvent to halonitrobenzenes to probe their reduction behavior and compare the reactivity of the radical anions with other nonaqueous solvent systems.

\section{EXPERIMENTAL}

The apparatus and experimental techniques for solvent handling and purification were described in detail in earlier papers. ${ }^{18-21}$ The supporting electrolyte used in the experiments, reagent grade potassium iodide, was dried at $120^{\circ} \mathrm{C}$ in an oven and then stored in a desiccator. The cell used for electrochemical measurements was a standard three-compartment cell with a Pt disk $\left(0.04 \mathrm{~cm}^{2}\right)$ working electrode for voltammetry and a large Pt-screen working electrode for coulometry. Details of components and design of a similar cell have been previously described. ${ }^{18,21}$ The electrochemical experiments were carried out with a PAR Model 173 potentiostat incorporating a Model 179 digital coulometer equipped with positive feedback for IR compensation and a Model 175 Programmer (Princeton Applied Research Corporation, Princeton, NJ). A Model $2000 \mathrm{X}-\mathrm{Y}$ recorder (Houston Instruments, Austin, Texas) was used to record the currentpotential curves. For fast scan rates, a Tektronix Model 564 storage scope was used. The experiments were performed at $-40^{\circ} \mathrm{C}$.

\section{RESULTS AND DISCUSSION}

o-Chloronitrobenzene. The cyclic voltammetric, $\mathrm{CV}$, results for the reduction of $o$-chloronitrobenzene at a Pt-electrode in liquid $\mathrm{NH}_{3}$ containing $0.1 \mathrm{M} \mathrm{KI}$ at $-40^{\circ} \mathrm{C}$ shows three reduction waves at $-0.4,-1.1$ and $-1.22 \mathrm{~V}$ vs. $\mathrm{Ag} / \mathrm{AgNO}_{3}(0.1 \mathrm{M})$. A typical cyclic voltammogram is shown in Fig. 1. The reversible wave at $-0.4 \mathrm{~V}$ had a peak separation of $50 \mathrm{mV}(46 \mathrm{mV}$ theoretically for a one electron reversible process at $\left.-40^{\circ} \mathrm{C}\right)$. The current ratio $i_{\mathrm{pa}} / i_{\mathrm{pc}}$ was $1.01\left(i_{\mathrm{pa}}-\right.$

Acta Chem. Scand. B 37 (1983) No. 5 


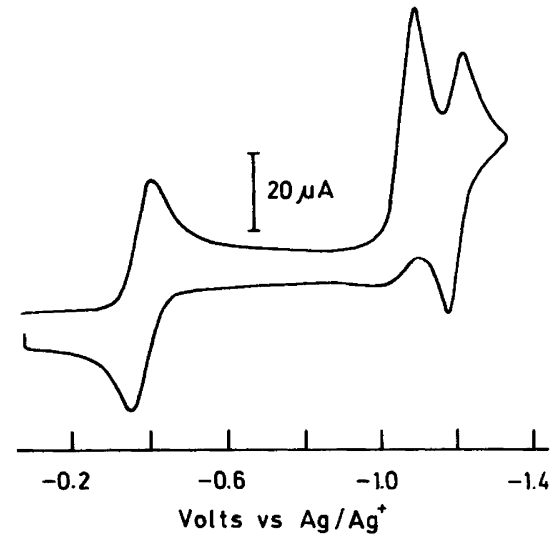

Fig. 1. Cyclic voltammogram for the reduction of $2.10 \mathrm{mM} o$-chloronitrobenzene in liquid $\mathrm{NH}_{3}$ at $-40{ }^{\circ} \mathrm{C}$. Sweep rate $200 \mathrm{mV} / \mathrm{s}$.

anodic peak current, $i_{\mathrm{pc}}$ - cathodic peak current). Controlled potential coulometry at $-0.60 \mathrm{~V}$ resulted in the passage of $0.96 \mathrm{~F} / \mathrm{mol}$. The electrogenerated radical anion had a bright orange color. A cyclic voltammogram of the solution following coulometry and initiated at $-0.6 \mathrm{~V}$ indicated the presence of the initial reversible wave. Coulometric oxidation at $-0.1 \mathrm{~V}$ resulted in an $n_{\text {app }}=0.93$ (where $n_{\text {app }}$ is the number of $\mathrm{F} / \mathrm{mol}$ ). The $\mathrm{CV}$ and coulometric results indicate that the first reduction wave corresponds to the production of a stable radical anion of $o$-chloronitrobenzene:<smiles>O=[N+]([O-])c1ccccc1Cl</smiles>

This species was stable on both the CV and coulometric time scale as indicated by the coulometric oxidation data.

These can be compared with those obtained by Fujinaga and coworkers (Ref. 21) from ESR studies using in situ generation of various halogenated radicals of nitrobenzene in DMF. The ESR data indicated that the electrogenerated radical anion of $o$-chloronitrobenzene was stable by the observation of its spectrum. However, if the radical anion was generated coulometrically, it was stable only for about $15 \mathrm{~min}$. The dehalogenation was evident by the appearance of lines for nitrobenzene radical anion in the ESR
Table 1. The effect of scan rate on peak potential of the second reduction wave of $o$-chloronitrobenzene in liquid $\mathrm{NH}_{3} . C=2.1 \mathrm{mM}, t=-40^{\circ} \mathrm{C}$.

\begin{tabular}{ll}
\hline Scan rate $(\mathrm{V} / \mathrm{s})$ & $-E_{\mathrm{pc}}($ Volts $)$ \\
\hline 0.05 & 1.10 \\
0.10 & 1.10 \\
0.20 & 1.11 \\
0.50 & 1.14 \\
1.00 & 1.14 \\
\hline
\end{tabular}

spectrum. The data presented for $o$-chloronitrobenzene show an enhanced stability of the radical anion in liquid $\mathrm{NH}_{3}$ over other nonaqueous solvents, which could be attributed to the low-temperature conditions of the reaction $\left(-40^{\circ} \mathrm{C}\right)$. No decomposition was observed even when the electrogenerated radical anion of $o$ chloronitrobenzene was allowed to stand at $-40{ }^{\circ} \mathrm{C}$ for $30 \mathrm{~min}$ as evident by oxidative coulometry, where essentially complete regeneration of parent with the same number of coulombs as in the previous reduction was found.

The second reduction wave at $-1.1 \mathrm{~V}$ as shown in Fig. 1 was irreversible even at scan rates up to $10 \mathrm{~V} / \mathrm{s}$. The peak potential of this wave shifted towards negative values by about $40 \mathrm{mV}$ for each 10 -fold increase in scan rate, Table 1 . The peak current, $i_{\mathrm{pc}}$, at a scan rate of $200 \mathrm{mV} / \mathrm{s}$ was about 1.8 times as large as that of the current of the first reduction wave. Although the peak potential of the third reversible wave was independent of scan rate, its peak height varied with $\mathrm{v}$. When the scan rate was slow, the peak was slightly larger. The electrolysis of the solution at $-1.12 \mathrm{~V}$ following the first electrolysis resulted in a dark brown solution and an $n_{\text {app }}$ of 2.1. The potential was carefully monitored for any possible shift during the electrolysis so as not to include the wave at $-1.22 \mathrm{~V}$ which could result in higher-than-predicted $n_{\text {app }}$-values. A potential scan performed following coulometry and initiated at $-1.12 \mathrm{~V}$ resulted in the appearance of a new reversible wave at potentials slightly negative of the first reduction wave. The reversible wave at $-1.22 \mathrm{~V}$ remained. The introduction of small amounts of nitrobenzene to the solution produced a cyclic voltammogram identical to that obtained after coulometry except that the waves were much larger. The analysis of the previous data clearly shows that the radical anion of $o$-chloroni- 
trobenzene is reduced at potentials more negative than $-1.0 \mathrm{~V}$ to produce ultimately nitrobenzene radical anion with the uptake of 2 electrons and a proton. The nitrobenzene radical anion is further reduced at -1.22 to the dianion. A possible reaction mechanism is:

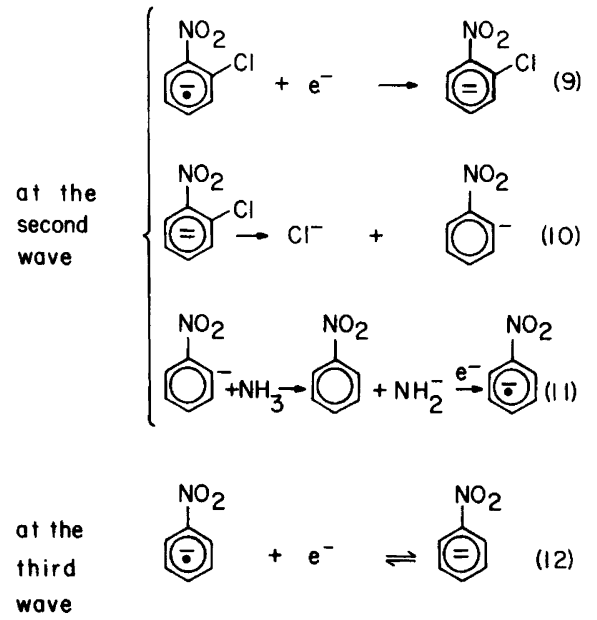

The rate constant for the halogen cleavage process, reaction (10), can be estimated from CV data to be about $1.2 \mathrm{~s}^{-1}$.

The slight increase in peak height of the third reduction wave with decreasing scan rate can be explained by the fact that as the scan rate is decreased, more time is available for the radical anion of $o$-chloronitrobenzene to dehalogenate. On the other hand, at high scan rates, the decomposition of the radical anion is slowed which inhibits nitrobenzene production. The absence of anodic current for the second wave, even at relatively high scan rates, implies that the halogen cleavage, reaction (10), is very fast and that the rate-determining step is the protonation of the carbanion, reaction (11).

$\mathrm{m}$-Chloronitrobenzene. The electrochemical reduction of $m$-chloronitrobenzene in liquid $\mathrm{NH}_{3}$ resulted in two reversible one-electron waves at -0.3 and $-1.09 \mathrm{~V}$ vs. $\mathrm{Ag} / \mathrm{AgNO}_{3}(0.1 \mathrm{M})$ as shown in Fig. 2. The peak potential for both waves showed no dependency on scan rate. The coulometric reduction of the solution at $-0.5 \mathrm{~V}$ produced the orange radical anion and an $n_{\text {app }}{ }^{-}$ value of 0.95 . The radical anion was very stable on the coulometric time scale, and could be oxidized back to the parent with an $n_{\text {app }}$-value of 0.92 . Controlled potential electrolysis at $-1.12 \mathrm{~V}$

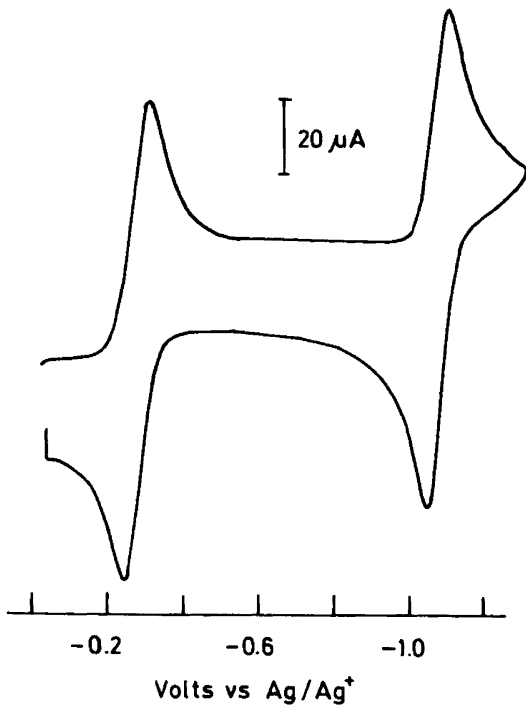

Fig. 2. Cyclic voltammogram for the reduction of $4.1 \mathrm{mM} m$-chloronitrobenzene in liquid $\mathrm{NH}_{3}$ at $-40^{\circ} \mathrm{C}$. Sweep rate $200 \mathrm{mV} / \mathrm{s}$.

gave a dark red solution after coulometry initiated at -1.12 and swept in a positive direction resulted in the production of two new reversible waves at $-0.42 \mathrm{~V}$ and at $-1.25 \mathrm{~V}$ (Fig. 3). The height of these waves was about $10 \%$ of that of the initial reversible waves. From the time

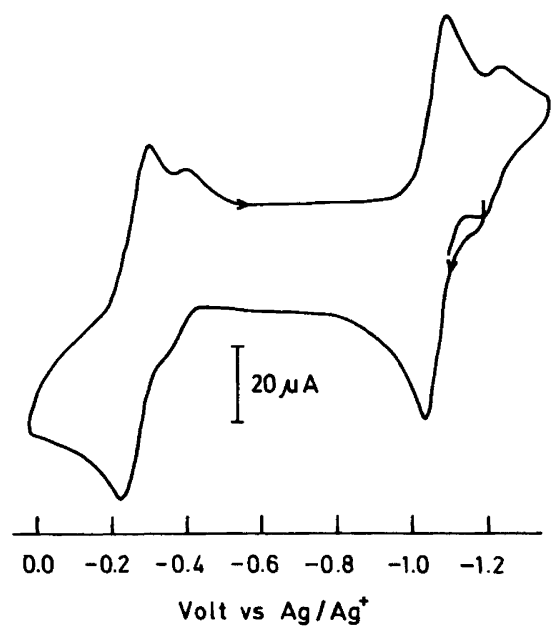

Fig. 3. Cyclic voltammogram for $m$-chloronitrobenzene following coulometric reduction at $-1.12 \mathrm{~V}$. Sweep rate $200 \mathrm{mV} / \mathrm{s}$. $C=4.1 \mathrm{mM}$, $t=-40^{\circ} \mathrm{C}$. 
required to complete the electrolysis, $15 \mathrm{~min}$, and the information regarding nitrobenzene production from cyclic voltammetry, the rate constant for the dehalogenation of the dianion was estimated to be $>10^{-4} \mathrm{~s}^{-1}$.

The results indicate that the mechanism of the reduction of $m$-chloronitrobenzene in liquid $\mathrm{NH}_{3}$ involves the transfer of single electron to form a stable radical anion of the parent. This species was extremely stable as it can be quantitatively reconverted to the parent compound. The dianion of $m$-chloronitrobenzene, although it was stable on the CV time scale, underwent slight decomposition after bulk electrolysis. This decomposition did not exceed $15 \%$, even when the generated dianion was allowed to stand for 30 min before coulometric oxidation was initiated. From the previous data, we conclude that the reduction of $m$-chloronitrobenzene in liquid $\mathrm{NH}_{3}$ involves two one-electron transfer steps to form a stable anion radical and a dianion. The dehalogenation of the dianion is very slow, so that a mechanism of the reaction can be written as:

$$
\begin{aligned}
& \overbrace{\mathrm{Cl}}^{\mathrm{NO}_{2}}+\mathrm{e}^{-} \\
& \overbrace{\mathrm{Cl}}^{\mathrm{NO}_{2}}+\mathrm{e}^{-} \\
& \overbrace{\mathrm{Cl}}^{\text {very }}
\end{aligned}
$$

Although the dianion of $m$-chloronitrobenzene was very stable, stepping the potential to the solvent cathodic limits resulted in a noticeable increase in nitrobenzene production. In fact, if the potential was held at $-2.2 \mathrm{~V}$ for a few minutes, the decomposition of halogenated dianion to nitrobenzene dianion was complete. This observation, although unusual, is not surprising, since the cathodic limit of $\mathrm{NH}_{3}$ involves the production of solvated electrons. This very strong reducing species probably causes electron addition to the halogenated dianion forming a trianionic species which rapidly cleaves a halide.

p-Chloronitrobenzene. The $\mathrm{CV}$ for the reduction of $p$-chloronitrobenzene is given in Fig. 4. The voltammogram indicates two successive one-

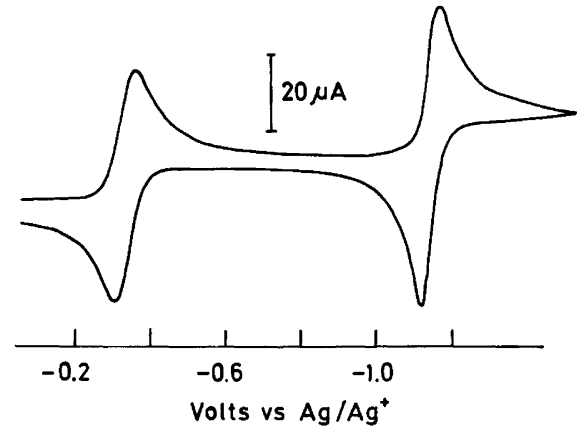

Fig. 4. Cyclic voltammogram for the reduction of $2.05 \mathrm{mM} p$-chloronitrobenzene in liquid $\mathrm{NH}_{3}$. Sweep rate $200 \mathrm{mV} / \mathrm{s}, t=-40^{\circ} \mathrm{C}$.

electron processes at -0.36 and $-1.16 \mathrm{~V}$. The peak potentials of these waves were not affected by changes in sweep rate. In addition, no new waves appeared even at relatively slow scan rates, e.g., $20 \mathrm{mV} / \mathrm{s}$. Controlled potential experiments were performed to investigate the stability of the radical anion and resulted in an $n_{\text {app }}=1.06$ for the first wave. No evidence of dehalogenation was observed, since $98 \%$ of the radical anion was converted to the parent by coulometric oxidation. Coulometric reduction at $-1.18 \mathrm{~V}$ produced an $n_{\text {app }}=1.85$ and a dark brown solution. A potential scan in the positive direction from $-1.18 \mathrm{~V}$ showed that the original reversible wave at $-0.36 \mathrm{~V}$ had disappeared and a new reversible wave appeared at $-0.42 \mathrm{~V}$. When the potential was swept negatively from $-1.18 \mathrm{~V}$, another reversible wave was present at $-1.22 \mathrm{~V}$ (Fig. 5). To confirm that these two new waves

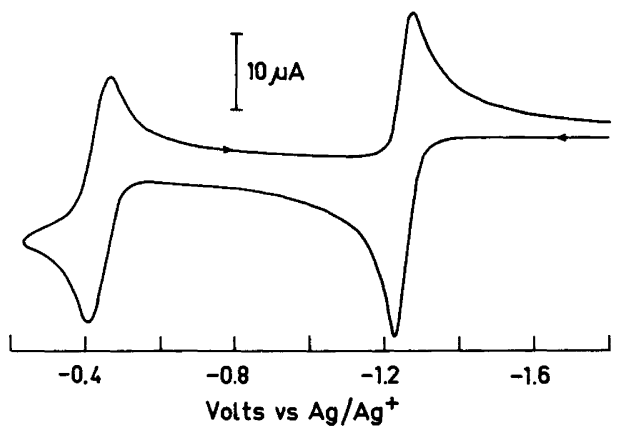

Fig. 5. Cyclic voltammetry following coulometric reduction at $-1.18 \mathrm{~V}$ of a $4.1 \mathrm{mM}$ solution of p-chloronitrobenzene in liquid $\mathrm{NH}_{3}$. Sweep rate $200 \mathrm{mV} / \mathrm{s}, t=-40^{\circ} \mathrm{C}$. 
were those of nitrobenzene, a $2 \mu \mathrm{l}$ sample of pure nitrobenzene was introduced into the cell. The cyclic voltammogram of the resulting solution was identical to that obtained before the addition of nitrobenzene with the exception that the peak currents were larger. The previous experimental data clearly demonstrate that $p$-chloronitrobenzene was reduced initially to a stable radical anion in liquid $\mathrm{NH}_{3}$. The addition of a second electron results in the formation of the dianion of the halogenated parent. This species, although stable on the CV time scale, undergoes dehalogenation and complete conversion to nitrobenzene upon electrolysis.

$\mathrm{m}$-Bromonitrobenzene. The $\mathrm{CV}$ behavior of $m$-bromonitrobenzene in liquid $\mathrm{NH}_{3}$ is shown in Fig. 6. Two one-electron reversible waves were observed at -0.30 and $-1.08 \mathrm{~V}$, with peak separations of $49 \pm 3 \mathrm{mV}$ and $43 \pm 3 \mathrm{mV}$, respectively. The peak potentials for both waves were independent of scan rate, characteristic of nernstian reactions. The extension of the potential sweep beyond $-1.2 \mathrm{~V}$ resulted in the appearance of a new wave at $-1.25 \mathrm{~V}$ and on scan reversal a second small oxidation wave at $-0.38 \mathrm{~V}$. A typical cyclic voltammogram of this system at different scan rates is shown in Fig. 7. At potential sweeps of less than $100 \mathrm{mV} / \mathrm{s}$, the wave at $-1.08 \mathrm{~V}$ began to lose its reversible appearance and, at the same time, the one at $-1.25 \mathrm{~V}$ increased in height. At sweeps $>500 \mathrm{mV} / \mathrm{s}$, however, the wave at $-1.08 \mathrm{~V}$ was totally reversible and the wave at $-1.25 \mathrm{~V}$

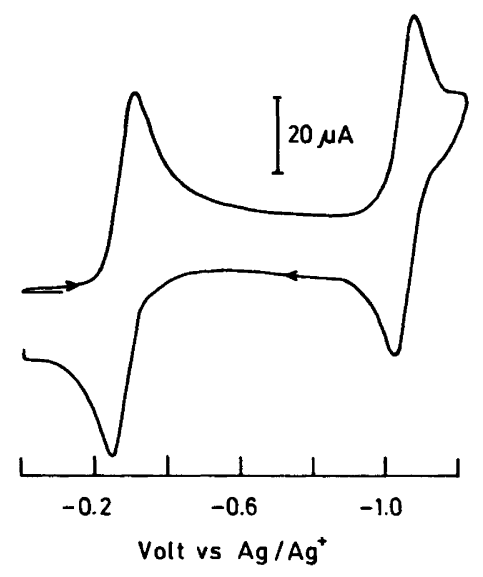

Fig. 6. Cyclic voltammogram for the reduction of a $3.75 \mathrm{mM}$ solution of $m$-bromonitrobenzene in liquid $\mathrm{NH}_{3}$. Sweep rate $200 \mathrm{mV} / \mathrm{s}, t=-40{ }^{\circ} \mathrm{C}$.
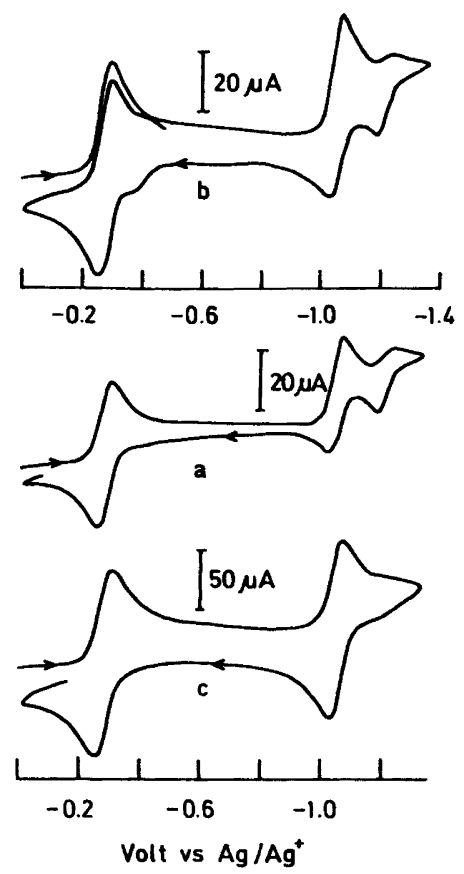

Fig. 7. Cyclic voltammogram for the reduction of $3.75 \mathrm{mM} m$-bromonitrobenzene at various sweep rates: (a) $50 \mathrm{mV} / \mathrm{s}$; (b) $100 \mathrm{mV} / \mathrm{s}$; (c) $500 \mathrm{mV} / \mathrm{s}$.

had completely disappeared. The data represents an ECE type process. The slow sweeps allow sufficient time for the dehalogenation and formation of nitrobenzene dianion. The electrolysis of the solution at $-0.40 \mathrm{~V}$ resulted in the formation of an orange radical anion with $n_{\text {app }}=1.10$. This species was stable to permit its quantitative conversion to the parent molecule. On the other hand, coulometric reduction at $-1.1 \mathrm{~V}$ resulted in the passage of $1.95 \mathrm{~F} / \mathrm{mol}$ and a deep red solution. The CV results following electrolysis indicated the presence of the two nitrobenzene waves discussed previously and observed for other halonitrobenzenes. The overall reaction sequence thus can be represented by:

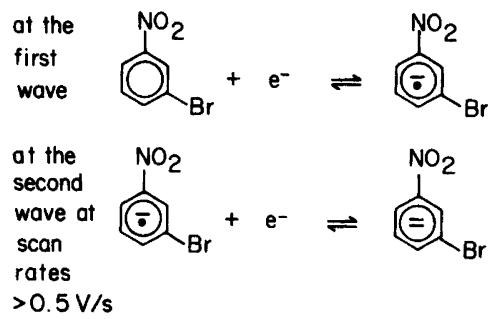




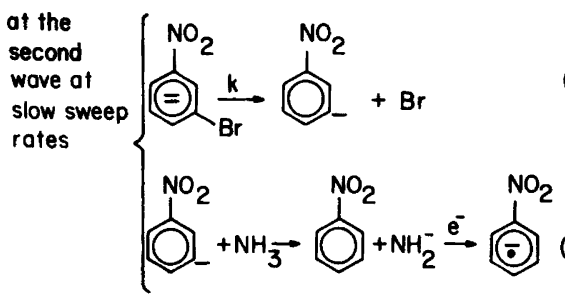

at the
third
wave

The CV data permits the estimation of a rate constant, $k$, for the halide elimination step, reaction (18), of the order of $10^{-2} \mathrm{~s}^{-1}$.

o-Iodonitrobenzene. The reduction of $o$-iodonitrobenzene in liquid $\mathrm{NH}_{3}$ occurred in three successive waves. Two reversible waves are observed at $-0.40 \mathrm{~V}$ and $-1.22 \mathrm{~V}$ and an irreversible wave at $-0.84 \mathrm{~V}$. The $E_{\mathrm{pc}}$ for the first reduction wave was completely independent of scan rate; the same was true for the third wave.

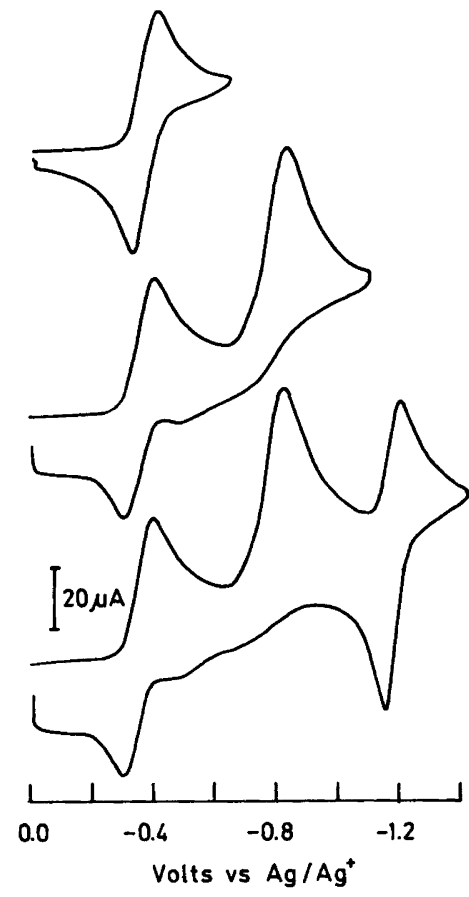

Fig. 8. Cyclic voltammogram for the reduction of $3.78 \mathrm{mM} o$-iodonitrobenzene in liquid $\mathrm{NH}_{3}$. Sweep rate $200 \mathrm{mV} / \mathrm{s}, t=-40^{\circ} \mathrm{C}$.

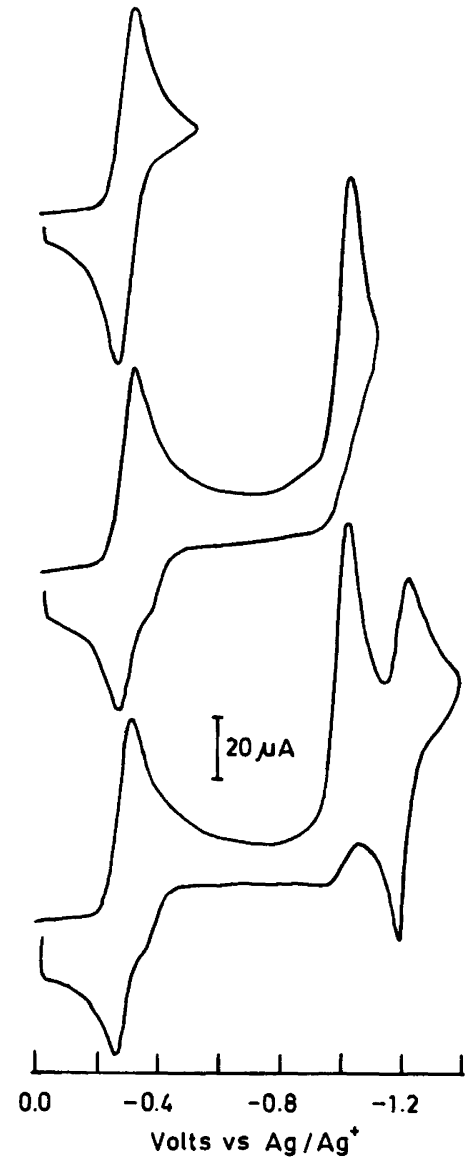

Fig. 9. Cyclic voltammogram for the reduction of $5.12 \mathrm{mM} m$-iodonitrobenzene in liquid $\mathrm{NH}_{3}$. Sweep rate $200 \mathrm{mV} / \mathrm{s}, t=-40^{\circ} \mathrm{C}$.

The irreversible wave at $-0.84 \mathrm{~V}$ was almost twice as large as the other two waves. The peak potential of this wave was dependent on scan rate where a 10-fold increase in sweep rate resulted in a $20 \mathrm{mV}$ negative shift in peak potential. No anodic current was observed for this wave even when the sweep rate was increased to $50 \mathrm{~V} / \mathrm{s}$. The cyclic voltammogram of the system is given in Fig. 8. Coulometry at $-0.6 \mathrm{~V}$ produced an $n_{\text {app }}=$ 1.6. The cyclic voltammogram following electrolysis and initiated at $-0.6 \mathrm{~V}$ resulted in the appearance of two reversible waves at -0.38 and $-0.20 \mathrm{~V}$, respectively. Addition of a $2 \mu \mathrm{l}$ of pure nitrobenzene caused an increase in the wave at $-0.2 \mathrm{~V}$. The second electrolysis experiment at $-0.90 \mathrm{~V}$ resulted in $n_{\text {app }}=1.51$ and a voltammo-

Acta Chem. Scand. B 37 (1983) No. 5 
gram showing only nitrobenzene waves at -0.28 $\mathrm{V}$ and $-1.10 \mathrm{~V}$. The voltammetric results lead to the conclusion that the reduction of $o$-iodonitrobenzene in liquid $\mathrm{NH}_{3}$ proceeds by the initial production of a stable radical anion. The coulometric experiments, however, show that this radical anion is partially decomposed to nitrobenzene in about $20 \mathrm{~min}$, the duration of the electrolysis. When the electrolyzed solution was allowed to stand at $-40{ }^{\circ} \mathrm{C}$ for an additional 15 min, no decrease in the height of the wave corresponding to $\mathrm{I}-\mathrm{C}_{6} \mathrm{H}_{4}-\mathrm{NO}_{2}^{-}$was observed.

m-Iodonitrobenzene. The $\mathrm{CV}$ results for the reduction of $m$-iodonitrobenzene in liquid $\mathrm{NH}_{3}$ were very similar to those obtained from the ortho isomer. However, the halogen cleavage process was much more rapid for the ortho derivative. The voltammograms given in Fig. 9 show three well-defined waves at $-0.32,-1.05$ and $-1.24 \mathrm{~V}$, respectively. As previously, a stable radical anion is formed as seen by the reversibility of the first wave on the $\mathrm{CV}$ time scale. The irreversible wave at $-1.05 \mathrm{~V}$ was about 1.7 times as large as the first reduction wave. Moreover, its peak potential shifted toward negative values with increasing scan rate. Evidence of dehalogenation of $m$-iodonitrobenzene species was also detected by a multicycle voltammogram which indicated that repeated cycling produced a new reversible wave at the same potential as that of the formation of the radical anion of nitrobenzene. The electrolysis of the solution at $-0.45 \mathrm{~V}$ resulted in the passage of $0.93 \mathrm{~F} / \mathrm{mol}$. The solution was orange and showed a CV behavior identical to the parent. A second coulometric electrolysis was performed at -1.10 $\mathrm{V}$ and an $n_{\text {app }}=1.78$ was obtained. The cyclic voltammogram of this solution following coulometry revealed two reversible waves at -0.42 and $-1.24 \mathrm{~V}$ corresponding to the two-step reduction of nitrobenzene. The results indicate that the reduction of $m$-iodonitrobenzene involves the production of a radical anion which is stable even on the coulometric time scale. The dianion, however, rapidly loses iodide ion to produce, ultimately, nitrobenzene. The CV data at varying sweep rates permit the calculation of a rate constant for the dehalogenation process as $2 \mathrm{~s}^{-1}$.

p-Iodonitrobenzene. Three reduction waves were observed for the reduction of $p$-iodonitrobenzene: a reversible wave at $-0.30 \mathrm{~V}$, an

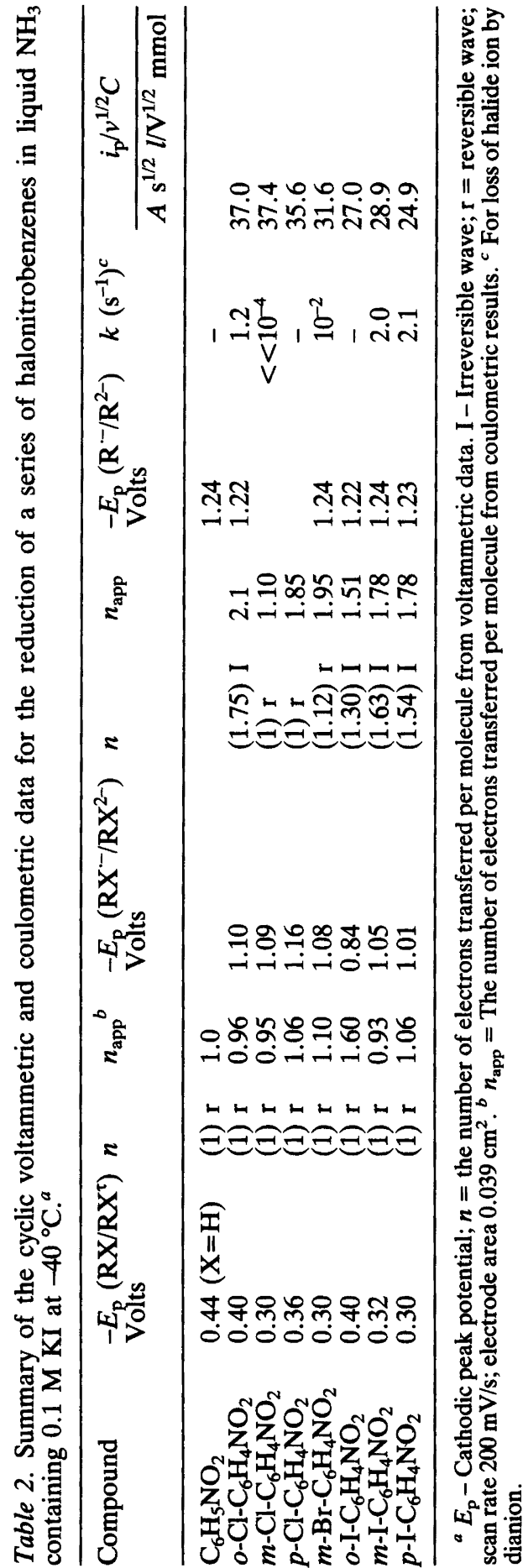

Acta Chem. Scand. B 37 (1983) No. 5 
irreversible wave at $-1.01 \mathrm{~V}$ and a reversible third wave at $-1.23 \mathrm{~V}$. These waves were almost identical with the ones obtained from the previous iodoisomers with the exception of small shift in the peak potentials. Controlled potential coulometry at $-0.50 \mathrm{~V}$ resulted in an $n_{\text {app }}=1.06$. The voltammogram of the solution following coulometry revealed the original waves. The bright red solution was then electrolyzed at -1.05 $\mathrm{V}$. The solution became dark brown and required the passage of $1.78 \mathrm{~F} / \mathrm{mol}$. As before, nitrobenzene was the final product of the reaction. The rate constant for the iodide cleavage process was $2.1 \mathrm{~s}^{-1}$.

\section{CONCLUSIONS}

The electrochemical reduction of a series of halonitrobenzenes in liquid $\mathrm{NH}_{3}$ containing 0.1 $\mathrm{M} \mathrm{KI}$ at $-40^{\circ}$ leads to the CV and coulometric data summarized in Table 2. The reduction of the chloronitrobenzenes series resulted in the following observations: The ortho derivative was initially reduced to a stable radical anion; however, the dianion was unstable, eventually yielding nitrobenzene. The meta derivative forms both a stable radical anion and dianion upon reduction. In fact, the latter was stable even at the coulometric time scale with only $10 \%$ decomposition observed after allowing the electrogenerated dianion to stand over a period of 15-20 min. The para isomer produced a stable radical anion on both the $\mathrm{CV}$ and the coulometric time scale; however, the electrolysis of the solution to produce the dianion resulted in quantitative conversion to nitrobenzene. $m$-bromonitrobenzene was the only bromo-compound studied. Cyclic voltammetry confirmed the formation of a stable radical anion and dianion. At the same time, evidence of slight decomposition was seen when the potential was scanned negative enough to allow the generation of the nitrobenzene dianion. Coulometric generation of the dianion produced nitrobenzene and bromide ion. The reduction of all three iodo derivatives was similar. The radical anions of the meta and para derivatives were stable enough to survive the coulometric experiments without apparent decomposition. On the other hand, the coulometrically generated radical anion of the ortho derivative indicated partial decomposition to nitrobenzene and iodide ion. The dianions for all three iodo isomers were unstable in liquid $\mathrm{NH}_{3}$ as evident by rapid iodide cleavage.

The results of the electroreduction of halonitrobenzenes in liquid $\mathrm{NH}_{3}$ can be compared with electrochemical studies in other nonaqueous solvents. In DMF and ACN, ESR measurements on electrogenerated radical anions of a series of halonitrobenzenes employing in situ methods resulted in the following observations. ${ }^{22,23}$ The meta- and para-chloro, meta- and para-bromo nitrobenzenes all produced ESR spectra characteristic of their radical anions. The ortho-chloro and ortho-bromo derivatives showed a decreased stability of the corresponding radical anion, probably because of steric effects. ESR studies have also indicated that all the iodo isomers undergo complete dehalogenation in $\mathrm{ACN}$ and DMF. However, recent studies of halonitrobenzene radical anions in DMF as a function of temperature ${ }^{14}$ suggest that appreciable stabilities of the radical anions (e.g. $m$ - and $p$ iodonitrobenzene) would be obtained at halflives greater than $5 \mathrm{~min}$ for $-40^{\circ} \mathrm{C}$.

In liquid $\mathrm{NH}_{3}$, one is able to prepare coulometrically stable radical anions from all the halonitrocompounds studied with the possible exception of the $o$-iodo derivative. The ability of halogenated compounds to resist halogen cleavage in $\mathrm{NH}_{3}$ could possibly be attributed to the low temperature conditions $\left(-40^{\circ} \mathrm{C}\right)$. Low temperature electroreductions of ortho and para iodonitrobenzenes in DMF have indeed shown an enhanced stability of the radical anions; however, this increased stability was accompanied by a large anodic-cathodic peak separation $(200 \mathrm{mV}$ in the cyclic voltammogram of orthoiodonitrobenzene at $-70^{\circ} \mathrm{C}$ ). Although the temperature effect could be the main contributing factor for the enhanced stability of radical anions in liquid $\mathrm{NH}_{3}$, dianions of halonitrobenzenes, which cannot be prepared in other nonaqueous solvents due to a rapid protonation rate, are stable in $\mathrm{NH}_{3}$ and allow the investigation of the halogen cleavage process.

Finally, the experimental results show that the rate at which the halonitrobenzenes radical anions are dehalogenated during electrochemical reduction is in the order: $m$-chloro $<p$-chloro $<$ $m$-bromo $<o$-chloro $<m$-iodo $\sim p$-iodo $<$ $o$-iodo. 
Acknowledgment. The support of this research by the National Science Foundation (CHE7903729) is gratefully acknowledged.

\section{REFERENCES}

1. Hawley, M. D. In Bard, A. J. and Lund, H., Eds., Encyclopedia of Electrochemistry of the Elements, Dekker, New York 1980, Vol. 14, Chapter 3.

2. Andrieux, C. P., Blocman, C., DumasBouchiat, J. M., M'Halla, F. M. and Savéant, J. M. J. Am. Chem. Soc. 102 (1980) 3806.

3. Alwair, K. and Grimshaw, J. J. Chem. Soc. Perkin Trans. 2 (1973) 1150.

4. Lawless, J. G. and Hawley, M. D. J. Electroanal. Chem. 21 (1969) 365.

5. Nadjo, L. and Savéant, J. M. J. Electroanal. Chem. 30 (1971) 41.

6. Van Duyne, R. P. and Reilley, C. N. Anal. Chem. 44 (1972) 158.

7. Bartek, D. E., Houser, K. J., Rudy, B. C. and Hawley, M. D. J. Am. Chem. Soc. 94 (1972) 7526.

8. Merz, A. Electrochim. Acta 22 (1977) 1271.

9. Grimshaw, J. and Trocha-Grimshaw, J. J. Chem. Soc. Perkin Trans. 1 (1974) 1383.

10. Savéant, J. M. and Thiebault, A. J. Electroanal. Chem. 89 (1978) 335.

11. M'Halla, F., Pinson, J. and Savéant, J. M. Electroanal. Chem. 89 (1978) 347.

12. Asirvathan, M. R. and Hawley, M: D. J. Am. Chem. Soc. 97 (1975) 5024.

13. Fujinaga, T., Arai, T. and Kitazawa, C. Nippon Kagaku Zasshi 85 (1964) 811.

14. Parker, V. D. Acta Chem. Scand. B 35 (1981) 655.

15. Grimshaw, J. and Trocha-Grimshaw, J. J. Electroanal. Chem. 56 (1974) 443.

16. Maksumoto, T., Sato, M. and Hirayama, S. Bull. Chem. Soc. Jpn. 46 (1973) 369.

17. DeMortier, A. and Bard, A. J. J. Am. Chem. Soc. 95 (1973) 3495.

18. Smith, W. H. and Bard, A. J. J. Am. Chem. Soc. 97 (1975) 5203; Ibid. 6491.

19. Smith, W. H. and Bard, A. J. J. Electroanal. Chem. 76 (1977) 19.

20. Vartires, I., Smith, W. H. and Bard, A. J. J. Electrochem. Soc. 122 (1975) 894.

21. Teherani, T. H. Dissertation, University of Texas at Austin, Austin 1979.

22. Fujinaga, T., Deguchi, Y. and Umemoto, $K$. Bull. Chem. Soc. Jpn. 37 (1964) 822.

23. Kitagawa, T., Layloff, T. and Adams, R. N. Anal. Chem. 35 (1963) 1086. 